\title{
Compliance Determinants of Mothers in Full Child Immunisation in Bangkalan District
}

\author{
Djazuly Chalidyanto ${ }^{1}$, Diah Indriani ${ }^{1}$, Fahmi Ashar $^{2}$ and Nurhasmadiar Nandini ${ }^{1}$ \\ ${ }^{1}$ Faculty of Public Health, Universitas Airlangga, Mulyorejo, Surabaya, Indonesia \\ ${ }^{2}$ District Health Office of Bangkalan, Bangkalan, Indonesia \\ djazulych@fkm.unair.ac.id
}

Keywords: Compliance, Immunisation, Mother's Characteristic, Health Service.

\begin{abstract}
Child immunisation is one of the cost-effective interventions in response to health problems and it provides protection against a variety of health problems for children. Universal Child Immunisation (UCI)'s achievement is a projection of the coverage of complete child immunisation. Child immunisation coverage in Bangkalan in 2011 had a gap compared to the target. The study aims to analyse the factors that influence mothers' compliance with child immunisation based on maternal characteristics, community support, and health workers in Bangkalan district. This research used a cross-sectional design and the populations were all mothers of children aged 12-24 months. The analysis was then continued using Path Analysis. The data was collected using a multi-stage sampling method. The samples included 360 respondents selected by the snowball technique. The results reveal that $37.3 \%$ of infants had been fully immunised on schedule and this indicates the mothers' compliance with child immunisation. The Path Analysis Model is able to predict immunisation compliance. The predictive factors are Community Support, Mother's Characteristics, Health worker, Service, and the Mother's Factors. Result showed that mother's characteristics and the health service directly affected the mother's compliance of child immunisation. Community support, health manpower and the mother's factors only have indirect effects.
\end{abstract}

\section{INTRODUCTION}

Child immunisation is one of the most effective health interventions in terms of cost. Budiman (2011) in Kompasiana (2012) said that in 1974, since the launch of the Expanded Program on Immunization (EPI) that included immunisation against seven diseases, immunisation has saved more than 20 million in two decades. UNICEF in the Report Card on Immunisation (2005) stated that vaccines have saved millions of children in the last three decades. Immunisation has becomes one of the programs for decreasing the child death rate in MDGs and programs of health development in Indonesia.

What Universal Child Immunisation (UCI) has achieved is a projection of the coverage of complete immunisation towards a group of infants. If UCI's coverage is put into a certain area, we can see the level of people or infants' immunity (herd immunity) against disease contagions that can be anticipated by immunisation (PD3I).
In the past few years, some mothers refused to bring their children to health care services for immunization even though it's free and provided by the government. The low mother's compliance to giving their children immunization caused by several factors such as mother's characteristics (age, education, income, attitude, etc), family support, poverty, lack of information about immunization, and other socio-economic factors (Ramayani, 2007; Falagas, 2008; Goofman \& Frerichs, 2000; Octaviani, 2015).

The UCI of Ministry of Health's target was $80 \%$ in 2008, and the UCI of East Java's target pursuant to the Minimum Standard of Service (SPM) up until 2015 was $\geq 95 \%$, and the UCI of Bangkalan District's target amounted to $90 \%$ in 2011 .

Table 1: Coverage of Immunisation in Bangkalan District for the January - December 2011 period.

\begin{tabular}{|c|c|c|c|}
\hline Immunization & Target & Coverage & $\begin{array}{c}\text { Coverage } \\
\text { Gap }\end{array}$ \\
\hline HB0 & $90 \%$ & $69.5 \%$ & $20.5 \%$ \\
\hline
\end{tabular}

